LANE, G. R. 1951. X-ray fractionation and chromosome breakage. Heredity, 5, I -35 .

LEA, D. E. 1946. Actions of Radiations on Living Cells. Cambridge.

RICK, с. м. I940. On the nature of X-ray induced deletions in Tradescantia chromosomes. Genetics, 25, 466-482.

SAX, K. 1940. An analysis of X-ray induced chromosomal aberrations in Tradescantia. Genetics, 25, 4-68.

sAx, K. 1941. Types and frequencies of chromosomal aberrations induced by X-rays. Cold Spr. Harbor Symposium, 9, 93-103.

SAX, K., AND ENZMANN, E. v. 1939. The effect of temperature on the frequency of X-ray induced chromosome aberrations. Proc. Nat. Acad. Sci. Wash., 25, 397-405.

SPARROW, A. H. 1949. X-ray sensitivity changes in meiotic chromosomes and the nucleic acid cycle. Proc. Nat. Acad. Sci. Wash., 30, 147-155.

\title{
REMARKS ON SAX AND LUIPPOLD
}

Sax's new data confirm the general conclusion drawn from previous experiments, that fractionation of X-ray dose reduces the yield of chromosome reunions. But, for the following reasons, I cannot accept the conclusions which Sax draws from the discrepancy between his results and my own. Nor can I take the view that the new experiments throw further light on the cause of the reduction. In the first place, in the experiments which Sax compares with my own, the temperature at which the material develops is not controlled nor is it even recorded so far as we are told. In the second place, Sax employs different material, a different intensity and a different time period between irradiation and fixation.

Since temperature affects the rate of physiological processes, time alone without controlled temperatures cannot serve as a measure in the comparison of experiments in which physiological processes are involved. The usefulness of comparing time-scaled experiments in which the temperature is uncontrolled, particularly if the other conditions and the materials differ in the different experiments, is therefore open to question.

A comparison between some earlier experiments carried out by Sax (Sax, K., I939, P.N.A.S., 25, 225-233) and the present experiments serves to illustrate this point. In these earlier experiments he observes that the rate of decrease in yields of aberrations with increasing intervals between fractions varies with the intensity. It is much greater at lower intensities of $25 \mathrm{r} / \mathrm{min}$. or $50 \mathrm{r} / \mathrm{min}$. than it is at I6o r/min. As Sax puts it "at high intensity, I6o $\mathrm{r} / \mathrm{m}$, there is little or no effect of the single rest period." These results are clearly pertinent to any comparison made between Sax's present experiments (intensity I $80 \mathrm{r} / \mathrm{min}$.) and mine (25 r/min.).

In discussing the temporary physiological effects of radiation (e.g. the effect on the rate of development and the effects on nucleic acid metabolism), I remarked that the timing and magnitude of these effects depend upon the dose and possibly the intensity, as well as upon the material used and the external conditions. If, as I have suggested, the reduction in breakage frequency with fractionation of dose is, in the main, the result of a physiological effect, the timing and magnitude of this effect would be expected to vary with all these factors. It is therefore not surprising that Sax's results differ from mine, but without a knowledge of the experimental conditions we are not in a position to attempt to interpret his results. 
Further experiments will doubtless show to what extent my explanation of my own results is correct, but they can do so only if they fulfil the essential conditions referred to in my paper. Insufficiently controlled experiments can only confuse the issue. To carry out experiments which fulfil these conditions is not easy, but it is in my opinion the only way to shed further light on the matter.

G. Roy Lane.

\section{REVIEWS}

HUMAN FERTILITY : THE MODERN DILEMMA. By Robert C. Cook. (Introduction by Julian Huxley.) London : Gollancz. [95I. Pp. 348. 21s.

The numbers of mankind are greater and are increasing faster than ever before. This increase is, as hitherto, differential with respect to different races and classes. But the races and classes that are favoured are not, as hitherto, those technically best fitted to maintain themselves but those least fitted to do so. The limits of food production set by the area of cultivable land, and the capacity to cultivate it efficiently, have therefore been reached and passed for certain peoples. Thus the problems brought to light by Malthus and Galton in the eighteenth and nineteenth centuries have, after some delay, come into focus together in the twentieth. How they have done so, and the catastrophe with which they now threaten us, it is Robert Cook's purpose to explain. At the same time he attempts to show how the genetic and evolutionary principles of Mendel and Darwin were discovered and how they apply to the situation.

The presentation is popular, the style is expansive, and the phrasing not always rigorous. It does not mean anything, or at least it ought not to mean anything, to say that "four-fifths of human mental ability is traceable to genetic factors" (p. 212). And sometimes the statistics run loose5 million immigrants into the U.S.A. is the maximum for 5 years, not for one year (p. 87). One wonders whether the death-rate in Italy is really 10.2 (p. 92) or lower than it has ever reached in England. And when it is said (p. 262) that in Japan : "In 1948 births exceeded deaths by nearly two million" should it not have been : r,400,00o? That, after all, is enough. It means 4000 a day, or a large and fully-loaded liner leaving every day for a foreign port, to keep the population stable. Or something greater than the maximum immigration rate into the U.S.A. in 1908 .

These are details. The principlcs, the arguments and the conclusions are clear and, I believe, inescapable. Indeed they are devastating. Whether it is in the history of Puerto Rico, in the picture of the visiting ladies advising General MacArthur on the subject of birth control in Japan, or in the account of Lysenko expounding the true doctrine of heredity, we see the size of the task that confronts those who would apply their knowledge of biology to save humanity from a not very remote disaster.

C. D. D.

SCIENTIFIC THOUGHT IN THE TWENTIETH CENTURY. Edited by A. S. Heath. London : Watts. 1951. Pp. 387. 42s.

The articles in this book on Statistics by R. A. Fisher, Zoology by P. B. Medawar and Genetics by E. B. Ford will be of value to readers of Heredity. The attempts to describe Social Medicine by Alice Stewart, Sociology by D. G. Macrae, and especially Social Anthropology by Meyer Fortes, 